\title{
Introduction: Intergenerational Transmissions: Cultivating Children's Agency?
}

\section{Joy Moncrieffe}

Readers may have anticipated that the 40th anniversary of the IDS Bulletin would have reviewed the last four decades of publications and re-presented their most influential messages. The IDS Bulletin is, indeed, reflective for it considers and builds on some of the core areas of research and policy advocacy that have, over the years, become central to the work of the Institute of Development Studies (IDS):

inequalities, poverty, power, social protection, transformational education, HIV/AIDS, gender, and climate change. However, the IDS Bulletin is, perhaps, best described as forward-looking, since it applies these issues to studies of the future, specifically the future of our children. It is forward-looking, too, in documenting emerging work - on and with children - that is occurring across the disciplines within IDS, as well as select strands of comparable work that are being developed outside the Institute. The IDS Bulletin explores a common theme that links these multidisciplinary areas of research: the question of intergenerational transmissions (IGTs) and, specifically, whether and how states, societies, development actors and parents, among others, are building the conditions under which children can imagine and realise better futures.

The concept, 'intergenerational transmissions', can convey an impression of path dependence. Where the focus is on children, it may evoke impressions of vulnerability, fragility and the weight of children's social, political and economic contexts. However, IGTs are not necessarily negative or uni-directional. Furthermore, children are known to be resilient: they can be vibrant agents of social change. The articles in this IDS Bulletin supply empirically based accounts of the conditions under which patterns of poverty, inequalities, violence and other such problems for development are transmitted across generations, as well as the conditions under which children, within these contexts, exercise 'agency'. There is no assumption that agency is inherent and automatic; the authors agree that agency is also cultivated. Furthermore, there is no assumption that agency is innately productive; rather, the articles demonstrate its complexity. The overarching questions are these:

1 How is agency being cultivated in different contexts, through what processes, and with what effects for children and for development?

2 What sorts of interventions are critical for disrupting harmful IGTs?
1 Intergenerational transmissions and agency
Much of the existing literature on
intergenerational transmissions focuses on poverty. ${ }^{1}$ The majority of these studies concentrate on household and intra-household factors - particularly the quantity and quality of asset transfers; however, there is increasing investigation of the broader contexts, including the terms under which people are incorporated in their societies and participate in the market (Bird 2007). Furthermore, the central argument, which Kabeer and Mahmud (this IDS Bulletin) outline, is that IGTs of poverty 'across generations occur through the transmission of various kinds of deficits' and can only be interrupted with sufficient investments in human capital. There is agreement that this investment in human capital 
is especially critical during childhood, as this is the point where investments are likely to have maximum impact on an individual's life chances.

Parents have important roles in determining when and how to invest in children. Becker and Lewis (1973) note that where there are resource constraints, parents are normally compelled to make a trade-off between the number of children in the family and the level and nature of human capital investments. This, for example, explains why education levels are known to rise where fertility levels decrease. In this IDS Bulletin, Kabeer and Mahmud revisit earlier discussions on intergenerational contracts between parents and children. They draw on Kabeer's (2001) discussion of 'affective transition', which suggests that parents are more willing to invest in children as mortality levels decrease and the likelihood of their children's survival beyond the early years of their lives increase. Parents are also better able to invest in their children as they gain access to and control over the means to ensure child survival and birth control. Under these conditions, parents are able to exercise a greater degree of personal agency and improve the quality of their investments. Yet, poverty does not always prevent parents from investing, particularly in their children's education. A range of factors influences parents' choices, including the severity of poverty (severely poor households tend to place less priority on education than the moderately poor); children's age and gender (e.g. cultural norms that privilege men normally result in greater emphasis being placed on boys' education); parents' education levels; household livelihood strategies; households' 'internal and external' vulnerabilities (parents' investments may depend on the types of shocks that the household encounters and the family's capacity to deal with them); levels of insecurity (insecurities may abound in the unsafe environments that those who live in conditions of severe poverty normally inhabit, including areas subject to frequent natural disasters and anti-social and violent neighbourhoods); parents and children's values and interests (parents and children have different attitudes towards education; the priority that children place on education also depends on the values of their peers, despite their parents' preferences). Therefore, Kabeer and Mahmud expand the conceptualisation of IGT of poverty beyond the material to include relational and subjective factors.
Sumner, Haddad and Gomez Climent's article in this IDS Bulletin helps to develop this broader and deeper understanding of IGTs. IGTs, they note, also involve transmissions of relations personal and social - and the subjective: values, perceptions and experiences. The authors argue that by focusing on the material, the traditional IGT approach also interprets agency in material terms and is, in that sense, deterministic: it 'implies a certain level of determinism because of strong assumptions about agency - for example, all preferences are pooled within the household [and] individuals tend to be predictably motivated by material incentives'. Individual agency, they note, is also a product of relationships and of the 'cultural norms, values, attitudes and behaviours that are transmitted across generations [and particularly] ... the degree to which people assume or identify themselves with them'.

Tadros (this IDS Bulletin) clarifies that intergenerational transmissions, such as of knowledge, values and ideologies, can take place through a variety of routes. While parents' roles in transmitting knowledge, values and norms are important, children are 'exposed to a multiplicity of other sources' (such as grandparents, peers and other social actors) and may be more affected by them. Tadros emphasises that it is important to move beyond the assumption that children are always the objects of transmission and incapable of influencing values and ideologies. She uses case examples to show that children can oppose the values that their parents endorse and also help to change their parents' outlook.

\subsection{Cultivating agency?}

Among the critical questions that the authors in this IDS Bulletin examine are: What forms of agency are being cultivated in the differing 'spaces' children inhabit? How is agency being cultivated, and with what effects? In response, various authors emphasise the importance of understanding (a) 'intersectionalities', and (b) the roles of power in cultivating agency.

\section{What is intersectionality?}

Banda and Chinkin (2004: 11) explain that 'what is now called intersectional discrimination seeks to capture both the structural and dynamic consequences of the interaction between two or more forms of discrimination or systems of subordination'. It exposes how discriminatory 
systems such as racism, patriarchy and economic disadvantage create 'layers of inequality that structure the relative positions of women and men, races and other groups'.

Intersectionality has been explained through the metaphor of a traffic intersection. Race, gender, class and other forms of discrimination or subordination are [among] the roads that structure the social, economic or political terrain. 'It is through these thoroughfares that the dynamics of disempowerment travel.'

These roads are seen as separate and unconnected but in fact they meet, cross over and overlap, forming complex intersections. [Children] who are marginalized by their sex, race, ethnicity or other factors [such as cultures and religion/faith] are located at these intersections. The intersections are dangerous places for [children] who must negotiate the constant traffic through them to avoid injury and to obtain resources for the normal activities of life. Where systems of race, gender and class domination converge ... intervention strategies based solely on the experiences of [children] who do not share the same class or race backgrounds will be of limited help to [those] who because of [factors such as] race and class face different obstacles. (Crenshaw 1991: 1241, quoted in Banda and Chinkin 2004: 11. The original text refers to women but because it applies equally to children has been changed accordingly here.)

Accordingly, in this IDS Bulletin, Greig acknowledges that deeply entrenched patriarchal ideologies continue to equate male identity with control over women. However, variables such as class, race and ethnicity play a role in the social and cultural construction of male identities. By recognising such 'intersectionalities', it becomes possible to delve beneath broad generalisations about gender identities and to understand, for example, why young men in lower income groups in Rio de Janeiro's favelas (slums) might gain less from education than young men who occupy higher income brackets and, therefore, why youth within favelas appear to not prioritise education. Likewise, Hossain emphasises how variables such as class and gender affect public policy on child labour in Bangladesh. Education policies have resulted in increased access for girls over the last two decades but it has not curtailed child labour among boys from the poorest classes. For these boys, the remuneration from work remains attractive, compared with the poor quality of education that is available to them. Furthermore, the absence of social sanctions against child labour adds 'legitimacy' to the practice. In their article, Edström and Khan discuss the importance of voice and visibility for children affected by HIV/AIDS and also the need for deep analysis of how and why different categories of children - such as orphans, the less educated and those who suffer from various forms of inequality that have been transmitted across generations - are especially vulnerable. Moncrieffe highlights how deepseated beliefs about race can affect how children perceive themselves and imagine their futures, with very serious - though largely overlooked implications for their development.

\section{Power and agency}

Careful analysis of how different categories of children experience and respond to inequalities, poverty, inclusion and exclusions, for example, reveals much about power relationships and dynamics. They show how overt ${ }^{2}$ forms of power, 'hidden' relationships of power (operating from behind the scenes), and 'invisible/internalised power' influence children's perceptions of themselves and others, as well as how and when they exercise agency. Invisible power is, arguably, the most intractable form of power to curb:

Probably the most insidious of the three dimensions of power, invisible power shapes the psychological and ideological boundaries of participation. Significant problems and issues are not only kept from the decisionmaking table but also from the minds and consciousness of the different players involved, even those directly affected by the problem. By influencing how individuals think about their place in the world, this level of power shapes people's beliefs, sense of self and acceptance of the status quo - even their own superiority and inferiority. (Adapted by Just Associates from Veneklasen and Miller 2002 and quoted in Gaventa 2006: 29.)

The actor-oriented approach to understanding power and agency tends to overestimate people's abilities and capacities to exercise their own choice. However, as Fox (1996) explains, 'state and society actors can provide positive or negative sanctions' that influence agency. This is 
an important caution that tempers the view that people are always capable of persisting despite the odds and of effectively counteracting even the most obdurate of boundaries to action. Similarly, Wood (2003: 456) calls for 'anthropological insight into capacities for social action', by which he means a study of the conditions under which different categories of people develop their capacity for social action, and exercise agency. This IDS Bulletin aims for a grounded interpretation of how agency works. It underscores that political agency is cultivated, particularly from childhood, and depends on a range of interacting factors, including power dynamics and relations, and how children conceptualise and perform in their roles as social actors at different periods in time.

Authors provide different, though complementary, perspectives on the dynamics of agency. Hossain (this IDS Bulletin), like Tadros and Greig, regards children and youth as persons with agency; therefore, boys and young men have roles in their own socialisation - and can exercise choice.

Rather than merely being 'empty vessels awaiting their socialisation' (Greig, this IDS Bulletin), boys and young men may make different choices, depending on their social positions. However, agency - the capacity to make purposive choice can be restricted, where there are structural constraints; and depending on the weight and influence of the prevailing values, norms and belief systems. Tadros's case study provides a good case in point. Her article describes how children's views on gender equality were gradually changed through culture-sensitive 'participatory learning and engagement, support through mentoring, and through embedding the issue of gender equality in education in a wider framework relating to children's rights'. Tadros views this approach as transformative in process and in outcomes, unlike conventional ways of learning. Her case study also highlights the extent to which children were then able to instigate changes in values within their communities. Children discovered that while they were able to influence their parents and peers, they had little impact on the wider community, at least not until they appeared on television and were, therefore, regarded as more credible and having political weight. It was more difficult to influence people who had not seen the children on television. Their level of influence also varied, depending on the subject being tackled. For example, while they were able to prompt some school reforms, some children encountered resistance and severe rebuke when they attempted to challenge practices such as female genital cutting/mutilation. However, as the author underscores, the intergenerational transmission of human capital requires more than a change in values; it also requires urgent and committed attention to the structural impediments to equality: poverty, high cost of education and limited rewards for formal education.

In contrast to the positive forms of re-education that Greig and Tadros describe, there are articles in this IDS Bulletin that show how negative forms of agency can be cultivated, calculatingly, through relationships and perverse forms of socialisation, and how these coercive forms of socialisation can undermine children's resilience. Gayle's study, which was conducted in 11 garrisons (political strongholds) and five nearpoor communities in Kingston and St Andrew, Jamaica, analyses how young boys are being trained to become violent actors. He notes that boys who live at varying levels of proximity to the heart of the garrison (i.e. the headquarters) exhibit different patterns of behaviour: 'The closer the boys lived to the headquarters of political gangs or the garrison the more likely they were to have a direct and close relationship with the MP, the councillor and the political activists that oversee the "corners" of the communities', and 'the more violent their behavioural history', suggesting that training in political tribalism affects the boys' overall relationship with their peers. Gayle notes that boys who were well nurtured and supervised were better able to resist socialisation into violence in the garrisons.

Similarly, Honwana's article, 'Children in War', depicts how children can be conscripted and socialised into violence; how adult wars become children's struggles; and how the character of these forms of socialisation distorts children's life chances. Honwana questions the concept of agency, for while children can, in principle, exercise positive agency, where this is interpreted as resisting violence; children remain vulnerable to coercion and, therefore, must resort to tactical choices. Usefully, she differentiates between strategy and tactic. Following Michel de Certeau (1984), she acknowledges that people are able to make strategic choices when they have the autonomy 
and space to do so. Where persons lack the autonomy and control over physical and social space, they are forced to make tactical choices. Tactics, she agrees with de Certeau, are the 'art of the weak'. She emphasises that 'subordinated subjects must constantly manipulate events in order to turn them into opportunities'.

Honwana and Gayle both emphasise the roles of overt and coercive power: power as domination. However, their articles make more subtle references to power relations that operate from behind the scenes and to the processes through which power relationships become internalised, such that some children accept and live the roles into which they have been socialised. Moncrieffe elaborates on this intimate dimension of power. She agrees with Sarah White - in 'Thinking Race, Thinking Development' (2002) - that racial perceptions and inequalities continue to permeate development thinking and practice. However, she focuses on how racial perceptions and relations of inequality can be internalised, such that some children come to accept their racial inferiority. Moncrieffe maintains that racial self-stigmatisation may be more pervasive in some contexts, such as those in which children are so enclosed within their social, material and physical boundaries that they have limited prospects for engaging with persons from other races and classes and/or contexts where children witness and are socialised into accepting stark racial inequalities. However, Moncrieffe, Honwana and Gayle are all careful to point out that children who inhabit the same boundaries may exercise agency in different ways. In Gayle's case study, for example, boys who received good nurturing were better able to resist attempts to co-opt them into violence. In Honwana's case study, some children described the ways in which they attempted to resist, to act - tactically - even where there were substantive boundaries to action (Hayward 2000). In Moncrieffe's case study, there were children who dared to aspire, despite the apparent futility of their conditions. Such is the diversity of agency.

\section{Disrupting harmful IGTs}

This IDS Bulletin questions the extent to which policy interventions are, effectively, disrupting harmful IGTs and suggests that some interventions may be creating more damage (with more severe consequences for some categories of children than others). Kabeer and
Mahmud highlight the importance of stemming human capital deficits - such as investments in children's education - that are transmitted across generations and lead to this seeming path dependence in life trajectories:

The children of household heads (but not spouses) who are themselves uneducated are less likely to go to school. They are less likely to have worldviews that give value to education or to imagine a life for their children very different from the one that they themselves have had.

However, the values children place on their education also depend on how they are socialised in the wider communities:

Children are less likely to go to school when they grow up in communities in which very few children go to school, where the pressure of peers works to discourage school attendance, and where they perceive their own life chances in terms which provide few incentives to go to school.

Therefore, Kabeer and Mahmud are concerned to ensure not only that policies deal, concretely, with the material impediments to education access but also that there is dedicated effort to cultivate the values that would make education an attractive and important objective for families. The authors see a role for the government in raising education awareness, which could build on some of its earlier successful initiatives. In addition, they emphasise that attention must be given to improving parental involvement in their children's education, which requires new, inclusive and transformative approaches to education design and provision.

Bivens, Moriarty and Taylor focus on what transpires once children have access to education. They raise the important question of whether schooling is enabling children to 'learn for a life based on freedoms' or preparing them 'for a life of limited choices and unfreedoms'. The authors admit that education often entrenches the very inequalities that it should uproot and helps in the transmission of adverse power relations across generations; therefore, education can underpin poverty and inequalities. Furthermore, the emphasis on targets, measurements and assessments - this more quantitative, 
behaviourist approach to education - is not necessarily supportive of approaches that focus on 'learner transformation and empowerment, or approaches that engage directly with processes of social change within communities'. The humanist approach, which aims for the social development of learners, could help to 'round out' behaviourist approaches and provide 'space for more creative, student-focused pedagogies'. However, even such an integration may be insufficient to stimulate key processes in human development and social change at multiple levels. Transformative education, they note, can help to challenge injustices, marginalisation, disempowerment and embedded inequalities by ensuring that (i) 'learning becomes a dialogical process, rather than students adopting an attitude and habit of powerlessness in the classroom'; (ii) teachers learn to be more creative in their approaches, such that children's learning relate and is responsive to their contexts; (iii) community participation is increased with a view to encouraging actions that would tackle local development issues. Bivens et al. quote, appropriately, from one school inspector in Zambia: 'Sending every child to school is good but if the education they receive is irrelevant to their needs and that of their society, then that education has no credibility and is therefore questionable.'

This crucial issue of transformative education is tackled in other ways for, as Greig and Tadros both point out, radical changes in views at different levels of the society may be necessary for promoting gender equality among children which, these authors note, also depend on subjective issues, such as how boys and girls come to see themselves and exercise agency, in their transitions to manhood and womanhood. Moncrieffe expands on the importance of reeducating societal and development actors, while focusing closely on the children, in order to tackle racial inequalities at their roots. As she notes, 'challenging the patterns of meanings that sustain racial inequalities are crucial for ensuring that children have the best means, mechanisms and opportunities to exercise positive agency, as it is conventionally conceptualised; that is, to transform themselves and their circumstances'. Similarly, Honwana and Gayle both make it clear that radical reeducation and re-socialisation are important for reaching and influencing children who have been conscripted into violence.
Thus, the authors demonstrate, convincingly, the weight of the non-material on IGTs and children's agency. There is no suggestion that addressing the relational and the subjective should be kept separate from the material since there are critical interrelationships among them that will not be addressed by singular policy approaches. Conversely, various authors show how and why social, cultural, political and economic approaches can and need to be integrated. In their article, Sabates-Wheeler, Devereux and Hodges agree that transformative approaches must, necessarily, infiltrate social protection policies, which currently concentrate on short-term provisions to stem income and consumption deficits. Instead, social protection needs to take 'a long view'; that is, an intergenerational perspective in order to ensure sustainable improvements in wellbeing. This intergenerational perspective, as various authors have emphasised, is important for understanding the processes, including the social dimensions of vulnerability, that entrench chronic forms of poverty. Therefore, Sabates-Wheeler et al. outline a transformative social protection (TSP) agenda, which recognises that many of the current manifestations of vulnerability - such as malnutrition and low educational performance may well reflect 'intergenerational problems'. TSP aims to address the structural causes of vulnerability and the power relations and dynamics that underpin them. As the authors note, 'this implies transforming society to redress power relations that result in discrimination and social exclusion'. For example, the TSP agenda would go beyond cash transfers and include sensitisation campaigns to challenge and transform the behaviours that sustain gender inequalities and support legislative changes in order to prevent discrimination. The authors underscore that a transformative child-sensitive approach is critical if there is a sincere aim to break chronic poverty traps and accelerate progress towards childfocused Millennium Development Goals.

The majority of authors in this IDS Bulletin agree that there is need for considerably better investigation of the structural determinants of vulnerability which, they underscore, do not only contribute to human capital deficits but can also contribute to dislocation and violence. However, Edström and Khan remind us that studies of the determinants of vulnerability must, necessarily, 
include the perspectives of children and young people who, in spite of popular perceptions, are not passive objects but individuals who demonstrate resilience and agency in the face of numerous challenges. Accordingly, these authors reinforce the importance of new, more inclusive, approaches to research and policy processes, such that children - with their new visibility will be able to exercise voice, which would, in turn, fill critical gaps in current knowledge and in practice.

\section{Conclusion}

This IDS Bulletin explores the question of intergenerational transmissions and, particularly, whether and how states, societies, development actors and parents, among others, are building the conditions under which children can imagine and realise better futures.

The IDS Bulletin emphasises the following:

IGTs involve more than the quality and quantity of transfer of material assets; they also involve the patterns of relationships, 'cultural norms, values, attitudes and behaviours' that are transmitted across generations. Though norms, values, attitudes and behaviours are not fixed, impermeable or uncontested, they are important, as they influence how children function as social, political and economic actors.

- IGTs are not uni-directional: children also have the ability and capacity to influence parents and grandparents; moreover, they learn from a variety of actors (parents, grandparents, teachers, peers, etc.) and through a variety of processes of socialisation.

- Agency is cultivated among children, not only through the material conditions they inherit

\section{Notes}

1 For example, the Chronic Poverty Research Centre (University of Manchester and Overseas Development Institute) has been studying the factors that cause and those that can interrupt intergenerational and life-course poverty.

2 Earlier perspectives on power tended to concentrate on its visible dimension. However, Bachrach and Baratz $(1962,1970)$ went beyond this, arguing that power is not only but also through the relationships, values, norms and experiences into which they are socialised. While, in much of the literature, 'agency' assumes that people who are adequately empowered will act to improve their welfare - that is, to make purposive and positive self-actualising choices - people need not use power in this 'rational' way. For example, agency need not be positive; children can exercise their agency for negative ends; children may opt not to act at all, depending on how they come to regard their positions and possibilities.

What forms of agency are being cultivated in the different spaces children inhabit, and with what effects? The articles demonstrate how agency, in various forms, is cultivated in differing contexts. They show how the power relations that emerge and are constructed within certain environments influence children's perceptions, including of their capacities. Various authors emphasise that disrupting harmful IGTs requires addressing the structural determinants of vulnerability and recognising that these affect different categories of children in different ways. Moreover, policymakers must do much more to recognise the relational and subjective dimensions to vulnerabilities, poverty and inequalities, which necessarily involve dealing with power, in multiple dimensions. There is agreement that transformative approaches can provide a more comprehensive policy framework. However, this requires self-reflection on the part of development actors; analytical approaches that expose the multidimensionality of problems of development; integrated policy approaches; and genuine inclusion of parents, community members and children, who should not be regarded as mere objects of policy but as persons capable of making purposive, productive choices and translating these into actions.

displayed in open decision-making circles; instead, the powerful may exert influence behind the scenes, preventing 'unfavourable' issues from even reaching the agenda. They contend that this second, hidden, dimension of power is equally potent and often underinvestigated. The third dimension of power, invisible power, is arguably the most intractable form of power to curb. 


\section{References}

Bachrach, P. and Baratz, M.S. (1970) Power and Poverty: Theory and Practice, Oxford: Oxford University Press

Bachrach, P. and Baratz, M.S. (1962) 'The Two Faces of Power', American Political Science Review 56

Banda, Fareda and Chinkin, C. (2004) Gender, Minorities and Indigenous Peoples, London: Minority Rights Group International

Becker, G. and Lewis, H.G. (1973) 'On the Interaction Between the Quantity and Quality of Children', Journal of Political Economy 81: S279-88

Bird, K. (2007) The Intergenerational Transmission of Poverty: An Overview, CPRC Working Paper 99, Manchester: Chronic Poverty Research Centre Crenshaw, K. (1991) 'Mapping the Margins: Intersectionality, Identity Politics and Violence Against Women of Color', Stanford Law Review 43:1241-79

de Certeau, M. (1984) The Practice of Everyday Life, trans. S. Randall, Berkeley: University of California Press

Fox, J. (1996) 'How Does Civil Society Thicken? The Political Construction of Social Capital in Rural Mexico', World Development 24.6, June: 1089-103

Gaventa, J. (2006) 'Finding the Spaces for Change: A Power Analysis', in R. Eyben, C. Harris and J. Pettit (eds), 'Exploring Power for Change', IDS Bulletin 37.6

Hayward, G.R. (2000) De-Facing Power, Cambridge: Cambridge University Press

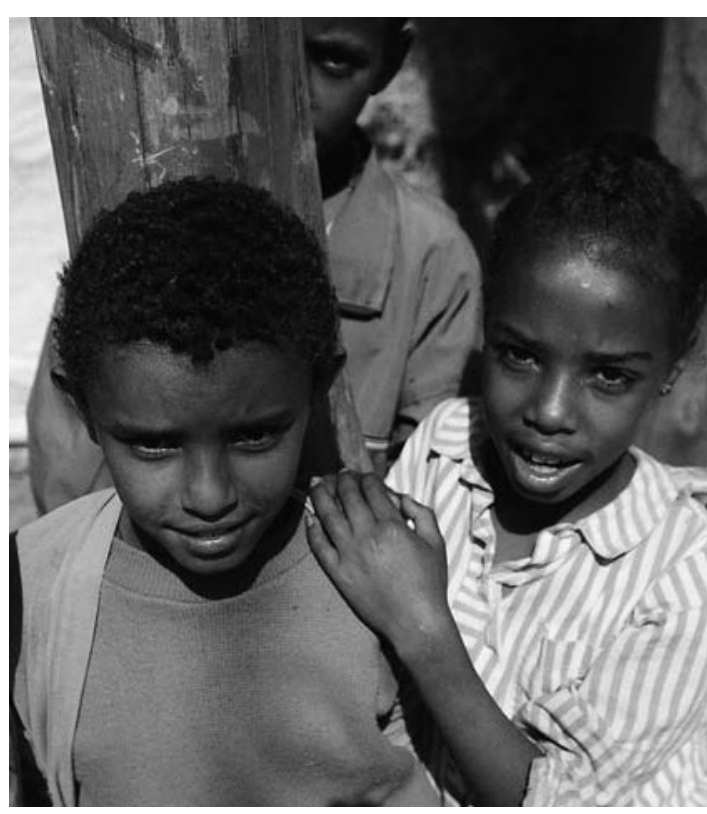

Children in village in Ethiopia: how do we cultivate their agency? Photo: Martin Moncrieffe

Kabeer, N. (2001) 'Intergenerational Contracts, Demographic Transitions and the Quantity-Quality Trade-off: Children, Parents and Investing in the Future', Journal of International Development 12.4: 463-82

White, S. (2002) 'Thinking Race, Thinking Development', Third World Quarterly 23.3: 407-19 Wood, G. (2003) 'Staying Secure, Staying Poor: The "Faustian Bargain"', World Development 31.3: 455-71 